It requires but a glance at the figures in this table to see that the aërial differs markedly from the aquatic part of the respiration. Even in the frog, in which the skin forms the only aquatic respiratory organ, the tendency is marked. The law appears to be unmistakably this, viz. that in combined aquatic and aërial respiration, the aërial part is mainly for the supply of oxygen and the aquatic part largely for the excretion of carbon dioxide. This law, which I stated in 1886 , has been confirmed by the repetition of old experiments and by many new ones made during the present summer. It is also confirmed by the experiments made on Lepidosteus in a different way by Dr. E. L. Mark, and published in I890. I therefore feel that this is the expression of a general law in nature.

From the standpoint of evolution we must suppose that all forms originated from aquatic ancestors, ancestors whose only source of oxygen was that dissolved in the water. As the water is everywhere covered with the limitless supply of oxygen in the air, there being 209 parts of oxygen in I000 parts of air as contrasted with the 6 parts of oxygen dissolved in I0oo parts of water, it is not difficult to conceive that in the infinite years the animals found by necessity and experience that the needed oxygen was more abundant in the overlying air, and that some at least would try more and more to make use of it. And as any thin membrane with a plentiful blond supply may serve as a respiratory organ to supply the blood with oxygen, it is not impossible to suppose that such a membrane, as in the throat, could modify itself little by little with ever-increasing efficiency; and that a part might become especially folded to form a gill and another might become sacular or lung-like to contain air. While I am no believer in the purely mechanical physiology which sees no need of more than physics and chemistry to render possible and explain all the phenomena of life, yet it is patent to every one that, although vital energy is something above and beyond the energies of physics and chemistry, still it makes use of these ; and certainly dear matter forms the material from which living is built. So given a living thing, it, in most cases, moves along lines of least, rather than of greatest, resistance; therefore if practically a limitless supply of oxygen may be obtained from the air and only a limited amount from the water, if anything that might serve as a lung is present, most naturally it (the animal) will take the oxygen from the air where it is in greatest abundance and most easily obtained. On the other hand, carbon dioxide is so soluble in water that practically a limitless amount may be excaeted into it; and as it is apparently somewhat easier, other things being equal, for it to pass from the liquid blood to the water than to the air, it seems likewise natural that the gills should serve largely for the excretion of the carbon dioxide into the water. This is the actual condition before us in these, and I believe in all other cases, of mixed or of combined aërial and aquatic respiration. And I believe, as stated above, that it may be laid down as a fundamental law in respiration that wherever both water and air are used with corresponding organs-gills for one and lungs for the other-that the aërial part of the respiration is mainly for the supply of oxygen, and the aquatic part largely for the getting rid of carbon dioxide.

It is not difficult to see in an actual case like that of the Ganoid Fishes (Amia and Lepidosteus) the logical steps in its evolution, by which this most favourable condition has been reached. A condition rendering these fishes capable of living in waters of almost all degrees of purity, and thus giving them a great advantage in the struggle for existence. But what can be said of the soft-shelled turtles, animals belonging to a group in which purely aërial respiration is almost exclusively the rule? Standing alone, this might be exceedingly difficult or impossible of explanation. The Batrachia (frogs, toads, salamanders, \&c.) all have gills in their early or larval stage, and most of them develop in the water, and are in the beginning purely aquatic animals. The adults must therefore, in most cases, repair to the water at the spawning season and frequently in laying the eggs they must remain under the water for considerable intervals. Being under the water, and the need of oxygen becoming pressing, there seems to be, by a sort of organic memory, a revival of the knowledge of the way in which respiration was accomplished, when, ai larvæ, their natural element was water, and they take water into the mouth and throat. This may be done by as highly a specialized and purely aërial form as the little brown tree-frog (Hyla pickeringii) or the yellow spotted salamander (Amblystoma punctatum). Another very interesting form, the vermilion-spotted newt (Diemyctylus), after two or three years of purely aërial existence goes to the water on reaching maturity and remains there the rest of its life, regularly breathing both by its lungs and by taking water into its mouth and throat. A still more striking exampie is given by Prof. Cope. The young siren almost entirely loses its gills, and later regains them, becoming again alnost completely aquatic in its habits as in the larval stage.

With these examples, which may be seen by any one each recurring year, is it impossible or difficult to conceive that in the struggle for existence the soft-shelled turtles found the scarcity of food, the dangers and hardships on the land greater than those in the water? Or, remaining constantly in the water, and advantageously submerged for most of the time, it gradually reacquired the power of making use of its pharyngeal membrane for obtaining oxygen from the water and excreting carbon dioxide into it as had its remote ancestors. And further, is it not intelligible that with capacious lungs, which it can fill at intervals with air containing so large $a$ supply of oxygen that it, like the other double or mixed breathers, should use its lungs to supply most. of the oxygen and its throat to get rid of much of the carbon dioxide?

Indeed it seems to me that if the evolution doctrine is a true expression of the mode of creation, then development may be in any direction that proves advantageous to an organism, even if the development is a reacquirement of long discarded structures and functions.

In closing, may I be permitted to say to the older biologiststo those familiar with the encouragements and inspirations that come with original investigation, that I trust they will pardon what to them is unnecessary personality or excess of detail in this address, for the sake of the younger ones among us, to whom the uphill road of research is less familiar. Judging from my own experience in listening to similar addresses by my honoured predecessors, it is helpful to know, when one is beginning, something of the "dead work," the difficulties and discouragements, as well as the triumphs, in the advancement of science.

\section{MINES AND MINING AT THE CHICAGO EXHIBITION.}

THE exhibition of objects relating to mines and mining at the "World's Fair" promises to be one of exceptional interest and importance. The following details about it were given by Mr. George F. Kunz in a paper read before the recent meeting of the American Association for the Advancement of Science :-

The building of mines and mining, which is entirely com. pleted, is 700 feet long and 350 feet wide, at an elevation of 25 feet above the main floor. On both sides is a gallery 60 feet wide, running the entire length of the building. Up to the present time there have applied for space in this building 26 foreign Governments and 36 States, these exhibits to be supplemented by "ther State and Government exhibits, such as that of Sweden in the Swedish building, the East Indian in the East Indian court, Illinois in their State building, \&c.

There will be a scientific collection of all the known elements, and with them a complete collection of all the known alloys of gold, silver, copper, zinc, tin, \&c., such as electrum, German silver, Babbits metal, fusible metal, and the thousand and one other, common and rare, used in the arts and industries. In the name of the Lake Superior copper mines, Prof. Alex. Agassiz has promised a complete exposition of ores, rocks, and processes, illustrating the occurrence mining, metallurgy of copper. There is now in preparation a coal collection to contain all varieties of coal, from every known occurrence in the United States. Petroleum will be shown as it never has been at any exhibition. The subject of abrasives of all kinds will form a special exhibit under the charge of Mr. T. Dunkin Paret, who has devoted his entire life to this subject, and is now making a special European trip to enlist the co-operation of foreign manufacturers and investigators to supplement the American exhibit.

The De Beers Mining Company of South Africa, who own and control mose than 95 per cent. of the entire diamond output, will make first a full and comprehensive exposition of diamond mining and the original blue stuff, a decomposed peridotite, enclosing carbonaceous shale, the matrix of the diamond, in great quantities. 'They will show it passing through

No. I I 99, voL. 46] 
the various washing machines, and every process separating the diamond from the matrix, in which exists a percentage of I carat 205 milligrams in a load of 1600 pounds. There will be a case containing over 10,000 carats of diamonds of all colours and of the various qualities, with a full series of the associated minerals and rocks. Every stage of the cutting and polishing of the diamond will be represented.

Nearly every mineral dealer in the United States has applied for space, and from the foreign trips and other preparations it is very evident that in the line of cabinet specimens and educational minerals the assembled collections will exceed those of any other exposition in importance.

One of the large gallery halls will contain a reference library for the use of visitors. This it is hoped will be a very comprehensive exposition of the literature of the subject of mines, mining, geology, and mineralogy. This is to be supplemented by historical portraits, documents, and other allied material.

An early history of mining and mining processes will be shown, starting with stone hammers and other aboriginal implements found in the copper mines of Lake Superior and the tur quoise mines of New Mexico, the old Mexican Pateo, to the most improved modern methods, and the remarkable sectional and glass models of mines, prepared by eminent mining engineers, used in the great mining lawsuits to prove their arguments.

One of the large corridor rooms in the gallery has been offered to the American Institute of Mining Engineers for their own use as a headquarters during the Exposition. They in turn may extend the courtesy to mechanical and civil engineers, as well as the English, German, French, and other foreign engineers whose hospitality they enjoyed in 1889 . There is every reason to believe that at least from 800 to rooo foreign engineers will visit the Exposition.

If only three-fourths of the promised exhibits are received, and there is every assurance that there will be many more coming, it may be safely said, even now, that the mining, metallurgical, geological, and mineralogical exhibits of the Columbian World's Fair will exceed in scientific importance and in extent the combined exhibits of the Centennial, the 1878 , 1889, the Paris and the Vienna Expositions, at least two-fold.

\section{UNIVERSITY AND EDUCATIONAL INTELLIGENCE.}

CAMBRIDGe.-Lord Walsingham, the High Steward of the University, has expressed his wish to give annually for three years a gold medal for the best monograph or essay giving evidence of original research in any subject coming under the cognizance of the Special Board for Biology and Geology. The offer having been accepted and the regulations for the medal having been approved, the Special Board for Biology and Geology give notice that the medal is offered for competition for the second time during the ensuing academical year. The essays are to be sent to the chairman of the Special Board (Prof. Newton, Magdalene College) not later than October 1,1893

The regulations for the medal are published in the Cambridge University Reporter, No. 908 (November 17, 1891), p. I86.

Sir R. S. Ball, Loundean Professor, will give his inaugural lecture in the Anatomical Theatre on Friday, October $2 \mathrm{I}$, at noon.

Dr. Cayley, Sadlerian Professor of Mathematics, resigns his place on the Council of the Senate on October 25.

The Council of the Senate recommend that the University of the Cape of Good Hope should be affiliated to Cambridge, on the same terms as those granted to New Zealand.

LonDON.- Four lectures upon "The Sun in its Relation to the Universe of Stars" will be delivered in Gresham College, at six p.m. on the evenings of October $25,26,27$, and 28,1892 , by the Rev. Edimund Ledger.

\section{SCIENTIFIC SERIALS.}

The Fournal of the Royal Agricultural Society of England, 3rd Series, Vol. iii., pt. 3.-Allotments and Small Holdings, by Sir J. B. Lawes and Dr. Gilbert. The authors have collected statistics relating to Allotments and Small Holdings in Great Britain. They point out that "within the present century there has been a great reduction in the number both of owners and of occupiers of farms not exceeding 50 acres in area such as it seems to be the object of the promoters of the Small Holdings Act of 1892 greatly to increase." After noticing the Rothamstead Allotments they proceed to discuss the conditions essential to the success of small holdings, and they conclude that ordinary rotation farming is much less suitable for smal holdings than dairy farming, the production of poultry and eggs, and market gardening when favourable conditions exist; the authors do not believe, however, that the system of small holdings will materially check the influx of agricultural labourers into the towns. This number of the Fournal also contains a short article by W. H. Hall on Small Holdings in France. Mr. Hall is "convinced that small holders (in England) have a great future before them as soon as they can be educated up to producing such articles as require to be consumed fresh, and will not bear long carriage." This last clause contains the key of the whole matter.-On the Vermin of the Farm, pt. ii., by J. E. Harting. In this paper the author has much to say in de fence of the mole (talpa europica), and of the weasel (mustelo vulgaris); there is little but condemnation, however, for the hedgehog, the stoat, and the polecat; the last-mentioned animal is now hardly known to most people, though the domesticated variety (the ferret) is common.-The Warwick Meeting of 1892 , by Dr. Fream, Official Reporter. This report shows the meeting to have been a good average one, except in the attendance of visitors on the last two days. Judge's reports show that in many cases the quality of the exhibits of live stock was far above the average. - Miscellaneous Implements Exhibited at Warwick, by T. H. Thursfield. -The Farm Prize Competition of I892, by J. B. Ellis.-Among the shorter articles is one deserving of careful attention; entitled New Modes of Disposing of Fruit and Vegetables, by Chas. Whitehead, in which are discussed the " evaporating" and the "canning" of fruit ; methods already in use in Queensland are described and discussed with reference to their adoption in this country when prices for fresh fruit are low.-Dr. J. W. Leather contributes a short article upon his method of detecting and estimating " castor-oil seeds in cattle foods." A weighed quantity of the suspected food is digested with hot dilute sulphuric acid (or $\mathrm{HCl}$, about 2 p.c.) for half an hour, washed free from acid, re-digested with a hot dilute solution of caustic soda, washed, and then finally treated with a quantity of bleaching powder. The husks of all seeds other than castor-oil seeds are bleached by this treatment, and any unbleached husks can be picked out and weighed.

Wiedeman's Annalen der Physik und Chemie, No. 9.-The principle of least effect in electrodynamics, by $\mathrm{H}$. von Helmholtz. -On the differences of potential of chains with dry solid electrolytes, by W. Negbaur.-On the reciprocity of electric osmose and flow currents, by U. Saxén.-Resonance phenomena and absorptive capacities of metals for the energy of electric waves, by V. Bjerknes.-Objective presentation of the Hertzian experiments with rays of electric force, by $\mathrm{L}$. Zehnder.-Dispersion and absorption of light according to the electrical theory of light, by D. A. Goldhammer.-On the measurement of high temperatures, by $\mathrm{L}$. Holborn and W. Wien. The apparatus was a modification of Le Chatelier's thermo-element, consisting of a combination of platinum and a platinum-rhodium alloy. This was calibrated by placing it inside the porcelain vessel of an airthermometer and compairing the readings, different thermo-couples were compared by exposing together in short porcelain tubes, two branches being welded together. The following fusing temperatures were deduced: gold $1072^{\circ}$, silver $968^{\circ}$, copper $1082^{\circ}$. - On the expansion of gases at low pressures, by G. Melander. Working with pressures ranging from 770 to $4 \mathrm{~mm}$, and temperatures from $0^{\circ}$ to $100^{\circ}$, the gases being kept at constant volume, the supposed law of constant decrease of coefficient of expansion with decreasing pressure was found not to hold good. That of air decreases down to $232 \mathrm{~mm}$, where it is 0.003659 , and then increases. That of carbon dioxide decreases down to $76 \mathrm{~mm}$, after which it increases, whilst that of hydrogen increases steadily.-Specific gravity and heat of fusion of ice, by J. v. Zakrzevski. The apparatus was a very delicate form of Bunsen's ice calorimeter. The specific gravity of ice at $-0.701^{\circ} \mathrm{C}$. was found to be 0.916710 . The cubical coefficient of expansion at that temperature was 0.000077 , which gives for the sp. gr. of ice at $0^{\circ} \mathrm{C}$ the value $0^{\circ} 916660$.- - On the theoretical conceptions of Georg Simon Ohm, by K. Von der Mithll.-Variation of the specific volume of sulphur with the temperature, by M. Toepler. 